\title{
The effect of tiotropium on exacerbations and airflow in patients with COPD
}

\author{
D. Dusser*, M-L. Bravo\# and P. lacono\#, on behalf of the MISTRAL study group
}

\begin{abstract}
This randomised, double-blind, parallel-group, 1-yr study compared the effect of tiotropium $18 \mu \mathrm{g}$ once daily $(n=500)$ and placebo $(n=510)$ on exacerbations, associated health resource use (HRU) and airflow limitation in chronic obstructive pulmonary disease (COPD) patients.
\end{abstract}

The mean \pm SD number of exacerbations during the past year was $2.14 \pm 1.40$, the mean weekly morning peak expiratory flow (PEF) was $259.6 \pm 96.1 \mathrm{~L} \cdot \mathrm{min}^{-1}$ and the mean forced expiratory volume in one second $\left(F E V_{1}\right)$ was $1.37 \pm 0.45 \mathrm{~L}$. Tiotropium significantly delayed the time to first exacerbation by $\sim 100$ days, reduced the proportion of patients experiencing more than one exacerbation by $17 \%$, and decreased the number of exacerbations by $35 \%$ and exacerbation days by $37 \%$ versus placebo. Tiotropium also decreased HRU versus placebo, as indicated by the significant reductions in the use of concomitant respiratory medications, antibiotics and oral steroids, and the number of unscheduled physician contacts. Mean weekly morning PEF improved significantly with tiotropium versus placebo from week 1 until the end of the study. At the end of the study, tiotropium significantly improved trough (pre-dose) FEV 1 , forced vital capacity, slow vital capacity and inspiratory capacity versus placebo.

In conclusion, tiotropium reduced exacerbations and associated health resource use, and improved airflow over 1 yr in chronic obstructive pulmonary disease patients.

KEYWORDS: Chronic obstructive pulmonary disease, exacerbations, health resource utilisation, peak expiratory flow, tiotropium

E xacerbations of chronic obstructive pulmonary disease (COPD) are a major cause of morbidity and mortality [1]. They are caused or triggered by a variety of factors, including bacteria, viruses and air pollution [2], and are characterised by acute worsening of symptoms, increased airway inflammation and deterioration of respiratory function [1]. As well as the burden to the patient, additional medication and/or hospitalisation for exacerbations add to the financial cost of treating COPD [3]. In addition, frequent exacerbations are associated with impaired health-related quality of life (HRQL) and a more rapid decline in lung function over time [4-6]. Interventions that reduce the severity or frequency of exacerbations and associated healthcare resource utilisation (HRU) should have a significant impact on both the patient's HRQL and the cost of treatment.

Physiological changes (e.g. decreases in peak expiratory flow (PEF) and forced expiratory volume in one second (FEV1)) immediately prior to an exacerbation are generally small and are not useful in predicting exacerbations [1, 4]. However, improved knowledge of the time course and duration of these physiological changes during an exacerbation could facilitate the administration of appropriate and timely care in the community and thus avoid hospital admissions.

Several studies have shown that maintenance treatment with long-acting bronchodilators (anticholinergics and $\beta_{2}$-agonists) may provide a protective effect against exacerbations [7]. Tiotropium is a once-daily anticholinergic bronchodilator that has been shown to improve FEV1, forced vital capacity (FVC), lung volumes, dyspnoea, HRQL and exercise capacity [8-12]. It has also been shown to reduce the incidence of exacerbations and delay the time to first exacerbation compared with either ipratropium or placebo [8-10]. In these studies, however, exacerbations were collected as adverse events. As a different approach, the present authors chose to solicit exacerbation data explicitly by the protocol, using a graded definition that included symptom and treatment intervention elements, and allowed sophisticated differentiation between the various severities of exacerbations.

A recent prospectively designed trial has shown that tiotropium reduces exacerbations in patients
AFFILIATIONS

*Groupe Hôspitalier Cochin, Assistance Publique Hôpitaux de Paris, Faculté Cochin Port-Royal, Université Paris, Paris, and

"Boehringer Ingelheim France, Reims, France.

CORRESPONDENCE

D. Dusser

Service de Pneumologie

Hôpital Cochin

27 Rue du Faubourg Saint Jacques 75679 Paris

Cedex 14

France

Fax: 33146338253

E-mail: daniel.dusser@cch.aphp.fr

Received:

May 302005

Accepted after revision:

December 062005

SUPPORT STATEMENT

Financial support provided by Boehringer Ingelheim France (Reims, France) and Pfizer France (Paris, France) 
with moderate-to-severe COPD [13]. However, this trial was restricted to a predominantly male sample study with severeto-very severe COPD and the follow-up period was only 6 months. Moreover, the various severities of exacerbations were not differentiated.

Results from previous trials have also shown that tiotropium reduced HRU compared with placebo and ipratropium, as indicated by reductions in the number of hospital admissions, days in hospital, unscheduled visits to healthcare providers and concomitant medication use [8-10, 13-16]. However, it is valuable to evaluate the impact of bronchodilators on HRU outcomes in single healthcare settings directly, rather than extrapolating data from multinational trials.

The objective of this analysis was to investigate the effects of tiotropium on the incidence of exacerbations, HRU and airflow limitation in patients with COPD in France. The relationship between PEF and exacerbations was also examined.

\section{METHODS}

\section{Study design}

This was a 1-yr, multicentre, double-blind, parallel-group study comparing the effect of tiotropium and placebo on exacerbations and associated HRU, and on airflow limitation. The trial (study protocol number 0205.214, assigned by Boehringer Ingelheim, Reims, France) was performed at 177 centres in France. An Institutional Review Board (the Comité Consultatif pour la Protection des Personnes dans les Recherches Biomédicales, Hôpital Cochin, Paris, France) approved the study protocol and all participants gave written, informed consent.

\section{Patients}

Male and female patients aged $\geqslant 40$ yrs old with a clinical diagnosis of COPD (pre-bronchodilator FEV1 30-65\% predicted and FEV1/slow vital capacity (SVC) $\leqslant 70 \%$ pred) [17] were eligible for inclusion in the study. Participants were also required to have a smoking history of $\geqslant 10$ pack-yrs and one or more exacerbations in the last year (as reported in the patient's medical file), but not within the 6 weeks prior to entering the study. Exclusion criteria were: history of asthma, allergic rhinitis or atopy; a recent lower respiratory tract infection or any exacerbation (within the previous 6 weeks); regular use of daytime oxygen therapy; oral corticosteroid use at unstable doses 6 weeks prior to entering the study or at a dose exceeding the equivalent of $10 \mathrm{mg}$ prednisone daily. In addition, those patients with a significant disease other than COPD that would put the patient at risk because of participation in the study, or a disease that would influence the results of the study, were not enrolled.

\section{Study protocol}

Following a 3-week screening visit, eligible patients were randomised 1:1 to receive either tiotropium $18 \mu \mathrm{g}$ once daily or placebo, delivered via the HandiHaler ${ }^{\circledR}$ (Boehringer Ingelheim, Ingelheim am Rhein, Germany) for 48 weeks. The study was concluded with a 2-week follow-up period. Patients were permitted short-acting $\beta_{2}$-agonists, as needed, for acute symptom relief. Concomitant use of inhaled corticosteroids (ICS) and oral steroids (at a dose of $<10 \mathrm{mg}$ prednisone daily or equivalent) was allowed if the dosage was stable for $\geqslant 6$ weeks before study entry. To treat COPD exacerbations during the trial, the investigators were permitted to administer any additional medication deemed necessary (excluding anticholinergics and long-acting $\beta_{2}$-agonists). During the treatment period, patients were not allowed to use oral or inhaled longacting $\beta_{2}$-agonists, inhaled anticholinergics (other than the study drug) or theophylline.

Detailed information on exacerbations of COPD, hospital admissions due to a COPD exacerbation, concomitant medications and non-scheduled contacts with physicians were collected at randomisation (day 1) as well as after 6, 12, 24, 36 and 48 weeks of treatment. HRU data specifically related to COPD were collected on a separate page of the case report form. An exacerbation was defined as the onset of at least one clinical descriptor (worsening of dyspnoea, cough or sputum production; appearance of purulent sputum; fever $\left(>38^{\circ} \mathrm{C}\right)$; appearance of new chest radiograph abnormality) lasting $\geqslant 2$ days and requiring a new prescription or an increase in the dose of $\beta_{2}$-agonists, antibiotics, corticosteroids or bronchodilators. The severity of an exacerbation was defined as severe, moderate or mild. A severe exacerbation was classified as an exacerbation requiring hospitalisation or an exacerbation plus one or more of the following criteria: FEV1 and/or PEF drop $>30 \%$ from baseline on $\geqslant 2$ consecutive days; partial pressure of oxygen $\left(\mathrm{Pa}_{2} \mathrm{O}_{2}\right)$ drops $\geqslant 10 \mathrm{mmHg}(\geqslant 1.33 \mathrm{kPa})$ from baseline or if $\mathrm{Pa}, \mathrm{O}_{2}$ drops to $\leqslant 60 \mathrm{mmHg}(\leqslant 7.98 \mathrm{kPa})$; partial pressure of carbon dioxide $\left(\mathrm{Pa}_{1}, \mathrm{CO}_{2}\right)$ increases $\geqslant 5 \mathrm{mmHg}(\geqslant 0.66 \mathrm{kPa})$ from baseline or if $\mathrm{Pa}_{1} \mathrm{CO}_{2}$ increases to $\geqslant 45 \mathrm{mmHg}(5.98 \mathrm{kPa})$. (FEV1, PEF and arterial blood gases were monitored in patients who were hospitalised with a severe exacerbation or if deemed necessary by the investigator.) A moderate exacerbation was classified as at least three clinical descriptors excluding severe exacerbations. A mild exacerbation was classified as one or two clinical descriptors.

In order to compare the results of this study more directly with those from previous exacerbation trials, a post hoc analysis was conducted, which used a more generalised classification of exacerbation severity based on HRU and treatment use. A severe exacerbation was classified as one requiring hospitalisation. A moderate exacerbation was defined as one requiring treatment with systemic steroids and/or antibiotics. All remaining events were classified as mild exacerbations.

Each patient performed daily PEF measurements in the morning prior to inhalation of the study drug and recorded the highest of three readings graphically on their diary card. They also recorded the number of puffs of "as-needed" rescue medication used in their diary and their respiratory condition using a graduated numerical scale (0: poor; 10: excellent). Patients were instructed to contact the investigator immediately if they experienced a negative change in their condition, and adequate treatment was prescribed if the investigator considered the patient to be having an exacerbation.

Spirometric tests were conducted at each clinic visit. FEV1, FVC, SVC and inspiratory capacity (IC) were recorded $30 \mathrm{~min}$ prior to dosing. All spirometric tests were conducted in triplicate and the highest measurements were used in subsequent analyses. 
Adverse events were monitored throughout the treatment period.

\section{Statistical analysis}

Analysis of covariance with terms for treatment was used for PEF and spirometric end-points, with baseline data as covariates. For PEF, the means of the measurements taken during the week before the treatment period were used as baseline data. An intent-to-treat (ITT), last-observation-carriedforward (LOCF) method was used for spirometric end-point analyses, except when patients discontinued due to worsening COPD, when the least favourable data prior to discontinuation were carried forward. All randomised patients with baseline and post-treatment data who took at least one capsule of study drug were included in the primary data set. An ITT, imputed method was used for analysis of PEF, whereby linear interpolation was used to estimate missing measurements. However, if data were not available on adjacent weeks, the LOCF method was used, and if patients discontinued due to worsening COPD, the least favourable data prior to discontinuation were carried forward.

The percentages of patients with one or more COPD exacerbation or hospital admission due to a COPD exacerbation over the 1-yr study period were analysed using Fisher's exact test. The number of COPD exacerbations, exacerbation days, hospital admissions, hospital days, physician visits, phone calls, oral steroid courses and antibiotic courses were analysed using the Wilcoxon-Mann-Whitney test. The duration of oral steroid and antibiotic courses were also analysed using the Wilcoxon-Mann-Whitney test. The time to first COPD exacerbation was analysed using the log-rank test. The percentage of patients requiring additional respiratory medication during an exacerbation was analysed using the Chi-squared test. Statistical significance was considered to be $\mathrm{p}<0.05$. Summary data are expressed as mean $\pm \mathrm{SE}$, unless otherwise stated. Prior to calculating descriptive statistics per group, quantitative descriptors of events were divided by the treatment exposure for each patient (and expressed as events per patient per yr by applying a multiplication factor of 365.25).

A sample size of 459 patients per group was calculated as adequate to detect a difference of $15 \mathrm{~L} \cdot \mathrm{min}^{-1}$ in mean weekly morning PEF based on an SD of $70 \mathrm{~L} \cdot \mathrm{min}^{-1}$. To ensure adequate safety exposure, a sample size of 1,000 patients (500 patients per group) was selected.

\section{RESULTS}

A total of 1,010 patients from 177 centres in France were randomised and treated, with 500 receiving tiotropium and 510 receiving placebo. More patients in the tiotropium group completed the trial than those in the placebo group $(76.6 \%$ versus $71.2 \%$ ). The two treatment groups were well matched at baseline (table 1 ). The mean $\pm \mathrm{SD}$ number of exacerbations during the past year was $2.14 \pm 1.40$. As per protocol, all patients had an exacerbation in the previous year $(60.7 \%$ of patients had two or more exacerbations) and $16.9 \%$ of patients had been hospitalised.

\section{Exacerbations}

The proportion of patients experiencing one or more exacerbation during the 1-yr treatment period was significantly lower

\begin{tabular}{|c|c|c|}
\hline & Tiotropium & Placebo \\
\hline Subjects $n$ & 500 & 510 \\
\hline Males \% & 89 & 87 \\
\hline Age yrs & $64.5 \pm 9.1$ & $65.0 \pm 9.5$ \\
\hline Duration of COPD yrs & $8.2 \pm 7.8$ & $8.5 \pm 7.7$ \\
\hline Current smokers \% & 27 & 24 \\
\hline \multicolumn{3}{|l|}{ Baseline spirometry } \\
\hline$P E F L \cdot \min ^{-1}$ & $261.5 \pm 96.1$ & $257.7 \pm 96.0$ \\
\hline FEV 1 L & $1.38 \pm 0.45$ & $1.36 \pm 0.44$ \\
\hline FEV $1 \%$ pred & $48.2 \pm 12.8$ & $47.6 \pm 12.5$ \\
\hline FVC L & $2.57 \pm 0.75$ & $2.54 \pm 0.77$ \\
\hline $\mathrm{FEV}_{1} / \mathrm{FVC}$ & $0.55 \pm 0.12$ & $0.54 \pm 0.12$ \\
\hline SVC L & $2.84 \pm 0.78$ & $2.82 \pm 0.85$ \\
\hline Exacerbations in last year & $2.16 \pm 1.43$ & $2.12 \pm 1.36$ \\
\hline $\begin{array}{l}\text { Hospitalisations due to exacerbation } \\
\text { in last year }\end{array}$ & $0.18 \pm 0.45$ & $0.21 \pm 0.50$ \\
\hline \multicolumn{3}{|l|}{ Pre-study medication for COPD \% } \\
\hline Any pulmonary medication & 97.0 & 96.9 \\
\hline Short-acting anticholinergics & 36.0 & 40.0 \\
\hline$\beta_{2}$-Agonist, oral & 5.0 & 4.3 \\
\hline Short-acting $\beta_{2}$-agonist, inhaled & 93.4 & 93.5 \\
\hline Long-acting $\beta_{2}$-agonist, inhaled & 31.0 & 32.5 \\
\hline Leukotriene receptor antagonist & 0.8 & 0.8 \\
\hline Oxygen & 3.0 & 3.3 \\
\hline ICS & 65.0 & 61.6 \\
\hline Steroids, oral & 2.4 & 2.0 \\
\hline Steroids, IV/IM & 0.0 & 0.6 \\
\hline Xanthines & 6.0 & 7.5 \\
\hline
\end{tabular}

Data are expressed as mean \pm SD unless otherwise stated. COPD: chronic obstructive pulmonary disease; PEF: peak expiratory flow; FEV1: forced expiratory volume in one second; \% pred: percentage of predicted value; FVC: forced vital capacity; SVC: slow vital capacity; ICS: inhaled corticosteroids; IV/IM: intravenous/intramuscular.

in the tiotropium group than in the placebo group $(17 \%$ reduction; $\mathrm{p}<0.01$ ) (fig. 1a). Patients treated with tiotropium had significantly fewer COPD exacerbations (35\% reduction; $\mathrm{p}<0.001)$ and exacerbation days $(37 \%$ reduction; $\mathrm{p}<0.001)$ than those treated with placebo (fig. $1 \mathrm{~b}$ and c). In addition, tiotropium significantly delayed the time to first COPD exacerbation by $\sim 100$ days compared with placebo $(\mathrm{p}<0.001$; fig. 2).

Severe exacerbations were observed in only 104 cases (85 of which fulfilled the hospitalisation criteria and 19, the arterial blood gas criteria). A sensitivity analysis for moderate and severe exacerbations was conducted. Tiotropium reduced the proportion of patients experiencing one or more moderate-tosevere exacerbation (by $30 \%$; $<<0.0001$ ), and decreased the number of both moderate-to-severe exacerbations (by 36\%; $\mathrm{p}<0.0001$ ) and moderate-to-severe exacerbation days (by $34 \%$; $\mathrm{p}<0.0001$ ) compared with placebo (fig. 1).

The post hoc analysis, using a more generalised classification of exacerbations, revealed similar results (table 2). Tiotropium reduced the proportion of patients experiencing one or more 

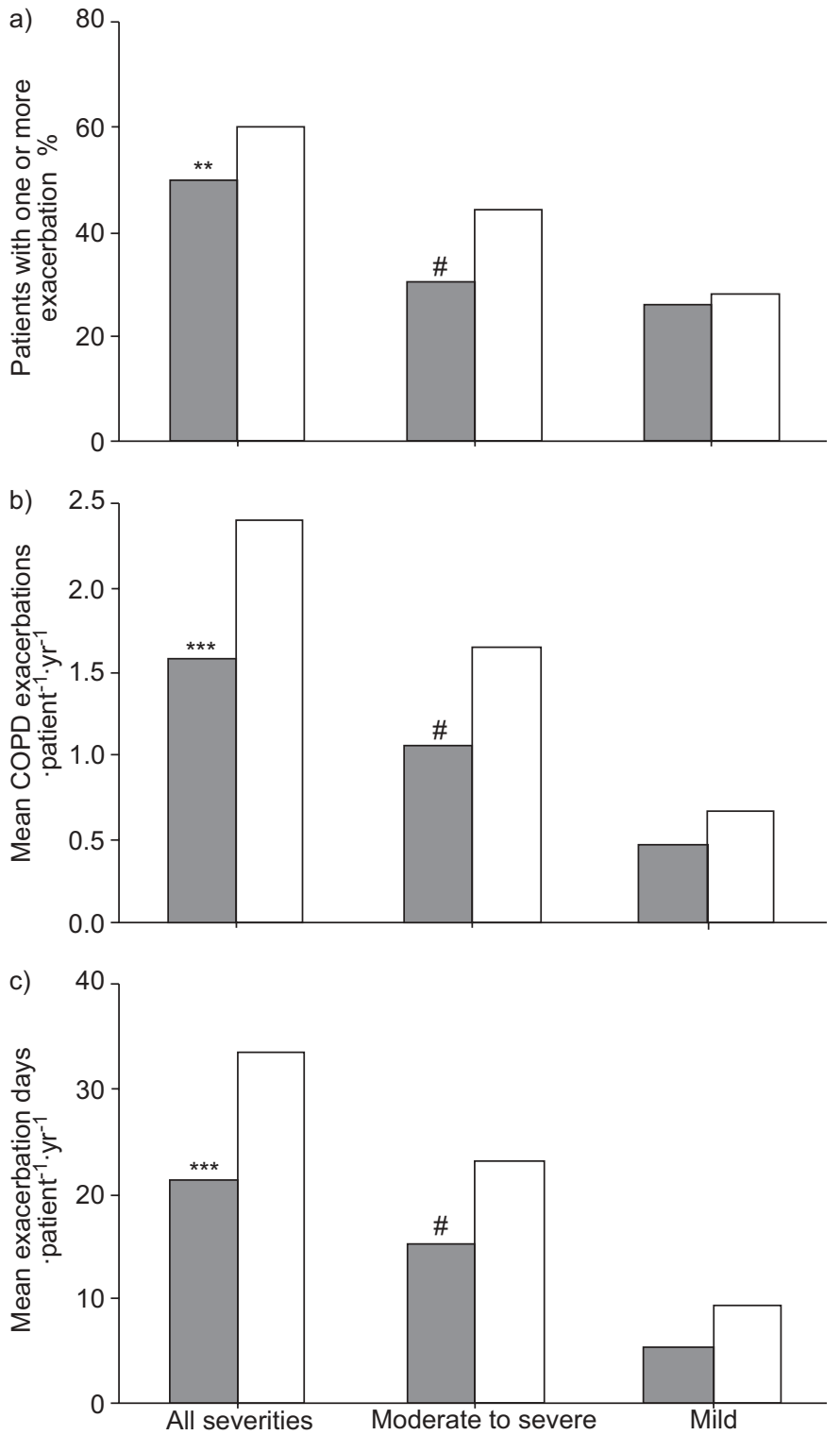

FIGURE 1. a) Percentage of patients suffering more than exacerbation in the 1 -yr treatment period. Mean number of b) chronic obstructive pulmonary disease (COPD) exacerbations and c) exacerbation days. Means are adjusted for treatment exposure. $\square$ : tiotropium, $n=497$; $\square$ : placebo, $n=506 .{ }^{* *}$ : $p<0.01$; ${ }^{* * *}$ : $p<0.001$; ${ }^{*}$ : $\mathrm{p}<0.0001$ versus placebo).

moderate-to-severe exacerbation (by 20\%, p<0.001) and reduced the number of moderate-to-severe exacerbations (by $35 \%, \mathrm{p}<0.001)$ compared with placebo.

Compared with placebo, tiotropium reduced the number of exacerbations, irrespective of COPD severity (based on FEV1 \% pred) at baseline (table 3). Tiotropium also provided a numerical reduction in the number of exacerbations, irrespective of ICS use during the trial and exacerbation history (based on number of exacerbations in the previous year) at baseline, compared with placebo (table 3). The improvement with tiotropium did not reach statistical significance in patients not receiving ICS during the trial or in patients with infrequent exacerbations in the previous year. The study was not

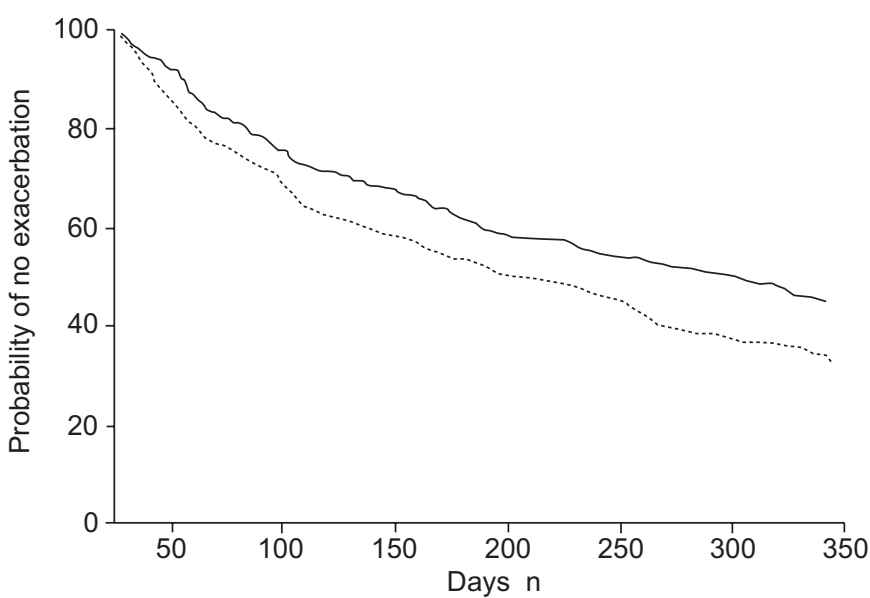

FIGURE 2. Kaplan-Meier estimates of the probability of remaining exacerbation-free. ——: tiotropium, $n=497$; -------: placebo, $n=506$. Time to first exacerbation: $p<0.001$ versus placebo (calculated using the log-rank test).

\begin{tabular}{|c|c|c|c|c|}
\hline \multirow[t]{2}{*}{ TABLE 2} & \multicolumn{4}{|c|}{$\begin{array}{l}\text { Percentage of patients with one or more } \\
\text { exacerbation and mean number of } \\
\text { exacerbations per patient per year according to } \\
\text { the post hoc classification of exacerbation } \\
\text { severity }\end{array}$} \\
\hline & & Tiotropium & Placebo & p-value \\
\hline \multicolumn{5}{|l|}{ All severities } \\
\hline Patients wit & one or more exacerbations \% & 49.9 & 60.3 & $<0.01$ \\
\hline Exacerbatic & s per patient per yr & 1.57 & 2.41 & $<0.001$ \\
\hline \multicolumn{5}{|c|}{ Moderate-to-severe } \\
\hline Patients wit & one or more exacerbations \% & 42.5 & 53.4 & $<0.001$ \\
\hline Number of & xacerbations per patient per yr & 1.10 & 1.69 & $<0.001$ \\
\hline \multicolumn{5}{|l|}{ Mild } \\
\hline Patients wit & one or more exacerbations \% & 13.1 & 15.6 & NS \\
\hline Number of & xacerbations per patient per yr & 0.47 & 0.72 & NS \\
\hline
\end{tabular}

adequately powered to detect differences between these subpopulations. However, in the subgroup of patients with moderate-to-severe exacerbations not receiving ICS during the trial, the difference between the placebo and tiotropium groups approached statistical significance $(p=0.06$; table 3$)$.

\section{Healthcare resource utilisation}

This study was not powered to detect a reduction in hospitalisations due to COPD exacerbations. However, compared with placebo, tiotropium resulted in numerically fewer hospitalisations and hospital days caused by COPD, but the differences between the groups were not statistically significant (table 4). Patients treated with tiotropium had significantly fewer unscheduled physician visits and phone calls than those treated with placebo $(\mathrm{p}<0.05$ for both; table 4$)$. There was no major difference in the range of medications used to manage exacerbations. However, fewer patients in the tiotropium group required additional respiratory medication during an 


\begin{tabular}{|c|c|c|c|c|}
\hline \multirow[t]{2}{*}{ TABLE 3} & \multicolumn{4}{|c|}{$\begin{array}{l}\text { Number of exacerbations per patient per year } \\
\text { according to chronic obstructive pulmonary } \\
\text { disease (COPD) severity and exacerbation } \\
\text { history at baseline, and ICS use during the trial }\end{array}$} \\
\hline & & Tiotropium & Placebo & p-value \\
\hline \multicolumn{5}{|c|}{ COPD severity } \\
\hline \multicolumn{2}{|c|}{ FEV1 $>50 \%$ pred $^{*}$} & $1.21(0.27)$ & $1.97(0.50)$ & $<0.01$ \\
\hline \multicolumn{2}{|c|}{ FEV $1 \leqslant 50 \%$ pred $^{\#}$} & $1.83(0.22)$ & $2.70(0.35)$ & $<0.05$ \\
\hline \multicolumn{5}{|c|}{ Exacerbation history } \\
\hline \multicolumn{2}{|c|}{ One exacerbation in the past $\mathrm{yr}^{\circ}$} & $1.24(0.23)$ & $1.75(0.34)$ & NS \\
\hline \multicolumn{2}{|c|}{ Two exacerbations in the past $\mathrm{yr}^{+}$} & $1.57(0.21)$ & $2.19(0.39)$ & NS \\
\hline \multicolumn{2}{|c|}{$\begin{array}{l}\text { At least three exacerbations in the } \\
\text { past } \mathrm{yr}^{f}\end{array}$} & $2.01(0.44)$ & $3.47(0.76)$ & $<0.001$ \\
\hline \multicolumn{5}{|c|}{ ICS use: all exacerbation severities } \\
\hline \multicolumn{2}{|c|}{ Receiving ICS ${ }^{\S}$} & $1.77(0.25)$ & $2.50(0.29)$ & $<0.01$ \\
\hline \multicolumn{2}{|c|}{ Not receiving ICS** } & $1.24(0.18)$ & $2.24(0.61)$ & NS \\
\hline \multicolumn{5}{|c|}{ ICS use: moderate-to-severe exacerbations } \\
\hline \multicolumn{2}{|c|}{ Receiving $\mathrm{ICS}^{\S}$} & $1.31(0.24)$ & $1.58(0.22)$ & $<0.01$ \\
\hline \multicolumn{2}{|c|}{ Not receiving ICS** } & $0.63(0.12)$ & $1.78(0.58)$ & 0.06 \\
\hline
\end{tabular}

exacerbation than in the placebo group $(\mathrm{p}<0.0001$; table 4$)$. In addition, patients treated with tiotropium required significantly fewer, and shorter, courses of both oral steroids $(p<0.01$ for both) and antibiotics $(p<0.001$ for both) for the treatment of COPD exacerbations than those treated with placebo (table 4).

Morning PEF and respiratory condition score were analysed for 15 days prior to, and for 8 weeks after, an exacerbation. Baseline PEF was defined as the mean morning PEF from day -28 to -14 prior to the start of the first exacerbation. Morning PEF declined rapidly 3-4 days prior to the reported start of an exacerbation in both the tiotropium and placebo groups (fig. 3a). The pre-exacerbation PEF was reached $\sim 4$ weeks after the start of the exacerbation in both groups. Baseline respiratory condition score was defined as the mean daily score from day -28 to -14 prior to the start of the first exacerbation. Similarly, respiratory condition score declined rapidly in the week preceding the exacerbation in both groups (fig. 3b). In contrast to PEF, however, pre-exacerbation respiratory condition score values were not reached, even after 8 weeks.

\section{Peak expiratory flow and spirometry}

Weekly morning PEF was significantly higher in the tiotropium group compared with the placebo group from week 1 until the end of the study ( $p<0.0001$ for all weekly intervals). The mean difference between the groups over the 1-yr study period was $25 \mathrm{~L} \cdot \mathrm{min}^{-1}$.

At the end of the treatment period, tiotropium improved trough FEV1 by $0.12 \pm 0.02 \mathrm{~L}(\mathrm{p}<0.0001), \mathrm{FVC}$ by $0.17 \pm 0.03 \mathrm{~L}$ $(\mathrm{p}<0.0001)$, SVC by $0.17 \pm 0.03 \mathrm{~L} \quad(\mathrm{p}<0.0001)$ and IC by $0.14 \pm 0.04 \mathrm{~L}(\mathrm{p}<0.001)$ compared with placebo.

\section{Use of rescue medication}

Patients receiving tiotropium self-administered approximately five fewer inhalations of rescue medication per week compared with those receiving placebo $(\mathrm{p}<0.01$ at all time points).

\section{Respiratory condition score}

Patients receiving tiotropium had higher respiratory condition scores compared with those receiving placebo ( $\mathrm{p}<0.05$ for 50 of the 52 weeks).

\section{Adverse events}

The proportion of patients experiencing an adverse event over the course of the 1-yr study was similar in both the tiotropium $(46.4 \%)$ and placebo (45.1\%) groups. The proportion of patients experiencing an adverse event leading to discontinuation was $3.0 \%$ and $3.5 \%$ in the tiotropium and placebo groups, respectively. The only adverse event consistently reported as possibly related to tiotropium was dry mouth, which was noted more frequently with tiotropium (4.0\%) than with placebo $(1.4 \%)$. Dry mouth led to discontinuation in one patient who was receiving tiotropium and in two patients who were receiving placebo.

TABLE 4 Healthcare resource utilisation during the study period

\begin{tabular}{|c|c|c|c|}
\hline Patients with at least one hospitalisation \% & 5.6 & 6.5 & NS \\
\hline Hospital days per patient per yr & $1.53(0.54)$ & $1.68(0.54)$ & NS \\
\hline Unscheduled physician visits per patient per yr & $1.3(0.1)$ & $2.2(0.3)$ & $<0.05$ \\
\hline Phone calls per patient per yr & $0.9(0.2)$ & $1.9(0.4)$ & $<0.05$ \\
\hline Oral steroid course duration days per patient per yr & $5.9(0.8)$ & $8.2(1.0)$ & $<0.01$ \\
\hline Antibiotic courses per patient per yr & $1.32(0.13)$ & $2.01(0.22)$ & $<0.001$ \\
\hline Antibiotic course duration days per patient per yr & $11.0(1.1)$ & $16.6(1.8)$ & $<0.001$ \\
\hline
\end{tabular}

Data are presented as mean (SE). NS: nonsignificant 

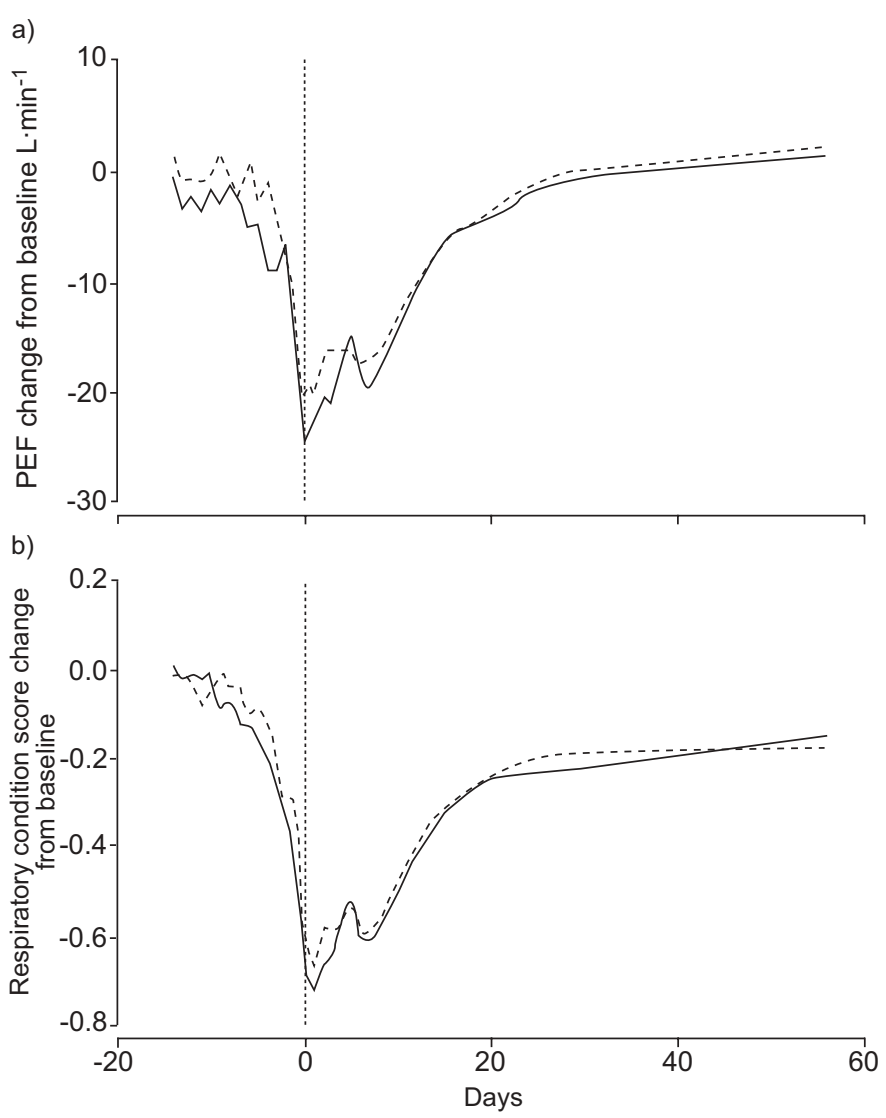

FIGURE 3. Mean change from baseline of a) peak expiratory flow (PEF) and b) respiratory condition score, from 2 weeks before to 8 weeks after an exacerbation. Data taken from all patients presenting with an exacerbation. —_: tiotropium; -: placebo; ................ start of exacerbation.

\section{DISCUSSION}

The goals of maintenance therapy in COPD include the relief of symptoms and the reduction of the number of exacerbations [18]. Exacerbations, especially those resulting in hospitalisation, are the main cost driver in COPD and frequent exacerbations are associated with impaired health status and a more rapid decline in lung function over time [4-6]. This 1-yr study found that maintenance treatment with once-daily tiotropium $18 \mu \mathrm{g}$ reduced exacerbations and associated HRU, and improved airflow limitation compared with placebo. As this study was conducted in a single healthcare system, any potential bias due to combining data from different systems was avoided. Surprisingly, relatively few females were included in this trial $(13 \%)$; however, this is probably a French phenomenon as a similar male:female ratio was observed in a recent randomised controlled trial [19] and in a "real world" study of patients with COPD in France [20].

Prevention and more effective treatment of exacerbations of COPD are the desirable outcomes, as the economic and social burden of exacerbations is extremely high. In this study, tiotropium significantly delayed the time to first exacerbation, reduced the proportion of patients experiencing an exacerbation and decreased the number of both exacerbations and exacerbation days compared with placebo. Patients enrolled in clinical trials may experience fewer exacerbations than usual as any deterioration in their condition may be detected and treated sooner. However, the rate of exacerbations was comparable in the placebo group with the year before trial entry and during the trial (2.12 and 2.41 events per yr, respectively).

Previous observations from long-term studies have shown that tiotropium significantly reduced the number of exacerbations and delayed the time to first exacerbation, compared with placebo or ipratropium [8-10]. Whereas in these former studies exacerbations were captured as adverse events, this study solicited exacerbation data using a grading system distinguishing events by severity. The overall incidence of exacerbations in this trial was higher compared with these previous studies (2.0 versus $0.8-1.3$ exacerbations per patient per year) [8-10] This is probably because only patients with at least one exacerbation in the previous year were eligible to enrol in the study. As the number of exacerbations in the previous year predicts exacerbation frequency [6], the patients enrolled in this trial may have been more prone to exacerbations than those in the previous studies.

Another potential reason for this finding is that the definition of an exacerbation used in this study differs somewhat from that reported in earlier publications, since the minimum duration of worsened symptoms was $\geqslant 2$ days as opposed to $\geqslant 3$ days and some additional clinical descriptors (i.e. appearance of purulent sputum, fever and appearance of new chest radiograph abnormality) were used to characterise exacerbations. The rationale for using a longer time-frame was to avoid simple fluctuations in the underlying disease being reported as exacerbations. However, a consensus definition of COPD exacerbations (which was published after the MISTRAL (Mesure de l'Influence de Spiriva ${ }^{\circledR}$ sur les Troubles Respiratoires Aigus à Long terme) trial was underway) states that the patient's respiratory and systemic symptoms should normally be worsened from the stable state and beyond normal day-to-day variation [21]. Further, the consensus document recommended assessing systemic clinical descriptors (i.e. increased body temperature, raised pulse/heart rate and impaired mental status) as well as respiratory ones when an exacerbation is suspected [21]. A more lenient definition of an exacerbation was used in this study to capture mild exacerbations. Despite this, the relative reduction in the number of exacerbations was similar in all severity groups and in the moderate-to-severe exacerbation subgroup.

In order to compare the results of this study more directly with those from previous exacerbation trials, a post hoc analysis was conducted, which used a more generalised classification of exacerbation severity based on HRU and treatment use. Using this classification, tiotropium significantly reduced both the proportion of patients experiencing a moderate-to-severe exacerbation and the number of moderate-to-severe exacerbations compared with placebo.

Tiotropium also reduced the number of exacerbations, irrespective of COPD severity (based on FEV1) at baseline. Furthermore, tiotropium lowered the number of exacerbations in patients who had frequent exacerbations in the previous year and in those receiving ICS during the trial. The improvement with tiotropium did not reach statistical 
significance in patients who had infrequent exacerbations in the previous year and in those not receiving ICS during the trial, but the study was not adequately powered to detect these differences. However, the results indicate that treatment with tiotropium is beneficial even in patients with less severe COPD (FEV1 $>50 \%$ pred), as well as patients with more severe disease (FEV1 $\leqslant 50 \%$ pred and/or frequent exacerbations). Moreover, the observed benefits may be independent of concomitant ICS use, as in the subgroup of patients with moderate-to-severe exacerbations not receiving ICS during the trial, the difference between the treatment groups was $\mathrm{p}<0.10$, indicating a trend in favour of tiotropium.

The mechanisms by which tiotropium reduces exacerbations remain to be identified. Tiotropium may have a direct antiinflammatory effect [22]. Alternatively, the reduction in exacerbations may be explained, in part, by the sustained bronchodilation and consequent reduction in lung hyperinflation afforded by maintenance tiotropium treatment. Airflow limitation (the most prominent physiological impairment in COPD) causes hyperinflation when there is insufficient expiratory time for adequate lung emptying. This causes the patient to feel dyspnoeic very quickly when the respiration rate is increased, for example, during exercise or an exacerbation. In this study, treatment with tiotropium led to significant improvements in PEF, FEV1, FVC, SVC and IC compared with placebo. These findings confirm previous observations from large-scale studies demonstrating that tiotropium provided significant improvements in airflow and lung volume parameters [8-12]. The present authors propose that the sustained reduction in hyperinflation (as indicated by a significant reduction in IC) may allow patients to withstand an insult for longer before experiencing intolerable dyspnoea (a key symptom during an exacerbation [23]). In other words, whereas patients may previously have perceived an acute deterioration in their condition as an exacerbation, after recalibration of their operating lung volumes with tiotropium treatment, their symptoms become better tolerated.

Improved knowledge of the time course and duration of physiological changes during an exacerbation would facilitate the administration of appropriate and timely care. In this study, PEF declined $\sim 3-4$ days prior to an exacerbation and did not recover to pre-exacerbation levels for $\sim 4$ weeks in both groups. Respiratory condition score also declined rapidly in the week preceding an exacerbation, but did not return to baseline values even after 8 weeks. In agreement with a recent study [24], decline in PEF is of limited use in predicting COPD exacerbations, as it occurred after the decline in symptoms (respiratory condition score). The 3-4-day delay between the start of the decline in PEF and the official start of the exacerbation (as defined by the investigator) may be the time required for the patient's condition to deteriorate enough to warrant contacting their physician. The finding that PEF (as well as perceived respiratory condition) took several weeks to return to baseline levels may have implications for the management of patients with COPD, as incomplete recovery of lung function and symptoms after an exacerbation may contribute to the gradual decline in lung function and symptoms that characterise COPD [1]. Therefore, it might be of value to monitor patients for several weeks after onset of even a mild exacerbation until recovery.
A reduction in the frequency of exacerbations or in the time to exacerbation is likely to reduce HRU, which, in turn, should reduce the cost of COPD management. In the present study, tiotropium significantly reduced HRU, as indicated by a significant decrease in the use of concomitant respiratory medication, antibiotics and oral steroids, as well as the number of unscheduled physician contacts. The inclusion criteria in this study were such that HRU focused mainly on outpatient treatment. Nevertheless, patients treated with tiotropium had numerically fewer hospitalisations and hospital days compared with those treated with placebo. Although the differences between groups were not statistically significant, the results are in agreement with those from previous studies, which have shown that tiotropium significantly delayed the time to first hospitalisation compared with ipratropium [9], and reduced the number of both hospitalisations and hospitalisation days compared with placebo [8, 9]. As hospitalisation is a large contributor to the cost of COPD, the addition of tiotropium to usual care therapy may reduce the economic burden of this disease (excluding the acquisition cost of the drug) [14]. Reducing physician visits and the use of concomitant medications are also of economic benefit.

In conclusion, this study found that, compared with placebo, administration of tiotropium $18 \mu \mathrm{g}$ once daily for 48 weeks reduced the frequency of exacerbations, with concomitant benefits in healthcare resource utilisation and improved airflow limitation. The beneficial effect of treatment with tiotropium was observed irrespective of inhaled corticosteroid use during the trial, chronic obstructive pulmonary disease severity and exacerbation history at baseline.

\section{ACKNOWLEDGEMENTS}

The authors gratefully acknowledge the provision of medical writing services from PAREXEL MMS.

The MISTRAL (Mesure de l'Influence de Spiriva ${ }^{\circledR}$ sur les Troubles Respiratoires Aigus à Long terme) study group is made up of the following investigators located in France. Abbeville: O. Leleu; Agen: G. Esculpavit; Aix Les Bains: O. Deschamps; Albi: B. Carme, J-J. Innocenti, F. Malaquin; Amboise: B. Lemmens; Amiens: V. Dinnoo; Angers: P. Moneger, L. Savary, R. Thuilier; Annecy: Y. Maria; Annonay: P. Gaillot; Antibes: J-M. Chavaillon, L. Lerousseau; Aubagne, Marseille: G. Thomas, D. Chollet; Aubergenville: P. Chaumier, C. Guelaud; Auch: J-C. Bersia; Auxerre: M. Piffoux; Avrillé: N. Tolstuchow Barbezieux: R. Meunier; Beausoleil: F. Bonnaud Belfort: D. El Baz, B. Richaud-Thiriez; Beziers: G. Durand, J-P. Dussol, J-C. Severac, M. Terol; Bobigny: F. Girard, D. Valeyre, H. Nunes; Bois Guillaume: J-F. Muir, A. Cuvelier; Bordeaux: J-M. Dupis, I. Hamy Marthan, P. Henrion, J. Vergeret; Boulogne Billancourt: J-F. Foult; Bourges: F. Bonte, J-C. Dassonneville, G. Adam, G. Desrivot, A. Levy, M. Mornet; Bourgoin-Jallieu: J-F. Bessonnat, J. Brunel-Crova; Bry Sur Marne: A. Bedin; Caen: P. Guillais, A. Guillo Lohan; Caluire: G. Chatte, M. Colas; Cambrai: S. Beaujot; Carcassonne: P. Chr. Carre, R. Perisse; Carpentras: M. Dedieu; Chalon Sur Saone: O. Jarry; Chambery: G. Gaudilliere; Chateauroux: O. Chauvin-Veron; Chauny: L. Bernabeu; Chevilly La Rue: M. Angebault, J-P. Homasson; Cholet: N. Grunchec, D. Krai, P. Masson-Maury; Clermont Ferrand: D. Caillaud; Colmar: M. Schaller; Cornebarrieu: P. Mourlanette, P. Debove; Courbevoie: V. Davy, C. Marie-Laure 
Debin; Dole: G. Sfeir; Douai: F. Pagnier, P. De Tauriac, A. Kaluzy; Dunkerque: C. Deroubaix, B. Mellin, G. Trochu; Eaubonne: P. Dournovo, S. Remili; Epernay: E. Bongrain, M. Carbonnelle; Ermont: M. Monchatre; Grasse: P. Dugue, M. Gomez-Figueredo, M-C. Dumon, B. Fouquert-Gau; Grenoble: J. Girey-Rannaud, M. Kuentz-Rousseaux, C. Grange, L. Chavez, B. Hamm, D. Rigaud, P. Satre; Guise: S. Kuissu; Hagondange: JM. Zordan; Henain Beaumont: E. Fournier, R. Roboubi; Langon: G. Fadlallah; La Rochelle: C. Gendreau; La Roche Sur Yon: O. Maurisset; La Teste: D. Boz, M. Denis; Le Cannet: C. Tabutin; Le Chesnay: R. Azarian, C. Camus-Cartraud, P. Kasparian, J-F. Le Calvez, P. Petitpretz; Le Mans: S. Girard, F-X. Lebas, I. Simon, F. Goupil, M. Pottier; Le Plessis Robinson: P. Herve; Libourne: B. Le Brozec, Y. Plantard; Lille: A-B. Tonnel, A. Scherperel, T. Perez, I. Tillie-Leblond, C. Deswarte-Antonius, J-J. Lafitte, C. Croxo, E. Dansin, P. Delecluse, P. Ramon; Limoges: G. Michel, P. Bourras, B. Wendling, F. Bonnaud, F. Vincent, B. Melloni, A. Vergnenegre, B. Eichler, F. Touraine; Lomme: A. Darras; Longjumeau: P. Assouline, A. Kabbani, G. Oliviero; Lorient: JY. Rigault; Lunel: C. Paillarguelo; Luneville: F. Chiny; Lyon: J-C. Guerin, A. Agresti, P. Nesme, M. Germain, P. Hyvernat, A. Penet, J-Y. Bayle, R. Ferrenq-Dubost; Marseille: H. Pegliasco, D. Charpin, M. Gouitaa; Martigues: H. Jullian; Maxeville: J-F. Bic, G. Issartel, L. Moreau; Metz: P. Zuck, G. Peiffer, M. Boukhana; Millau: F. Tronc; Montargis: C. Artigas, M. Daher; Montauban: B. Denis, F. Tirouvanziam; Montbeliard: C. Bertin, V. Robert; Mont De Marsan: B. Etcheverry; Montfermeil: Cyril Maurer, J. Piquet; Montigny Les Metz: D. Muller; Montivilliers: Chr. Dominique Guyonnaud, J. Quieffin; Montpellier: P. Chanez, L. Meziane, R. Clavel, P. Michel Coulet; Moulins: P. Duband; Nanterre: C. Appere, I. Caby, M. Saillour; Nantes: H-P. Audouin, S. Boutet Madrange, D. Payerne, J-Y. Jasnot; Narbonne: M. Benosmane, A. Fraisse, F. Trigui; Nevers: D. Herman, B. Meunier; Nice: A. Bettendorf, C. Perrin, B. Blaive, C. Clary, F. Lemoigne, I. Nicole, R. Tamisier, F. Macone, L. Limouse, B. Pigearias, B. Bugnas; Nimes: H. Faucal, O. Benezet, J. Dupouy, M. Yacono, M. Taulelle; Niort: D. Dutartre; Nogent Le Rotrou: P. Vivet; Noisy Le Sec: R. Kamte Yowou; Ollioules: P. Greillier, B. Terol, C. Pacchioni, J-J. Roujon, P. Salletaz, J-L. Vialla; Orleans: J. Durieu, A. Perche; Pamiers: J. Dakhil; Paris: D. Dusser, L. Tecucianu, N. Dufeu, T. Bui-Quang, M. Aubier, L. Hafi, F. Gagnadoux, M-L. Debin, G. Huchon, A. Mounejdi, J-C. Pujet, T. Baleyte Desfemmes; Perigueux: J-Y. Delhoume, F. Raad; Perpignan: B. Lirsac, M. Verdier, C. Sevette; Pierre Benite: F. Gormand, Y. Pacheco, S. Najda, R. Harf, S. Jerome; Poitiers: F. Caron, J-C. Meurice; Rambouillet: Y. Jerzy Scholz; Rang Du Fliers: M. Awad, C. Aron; Reims: J-B. Jouet, F. Masure, F. Passemard; Remiremont Cedex: Z. Bavelele, A. Kheir; Rennes: P. Delaval, C. Belleguic, B. Desrues, G. Le Garff, H. Lena; Romans Sur Isere: P. Gil; Rouen: G. Nouvet, S. Bota, J-B. Auliac, B. Melen, P. Denis; Saint Denis De La Reunion: F. Paganin, M-F. Angelini; Saintes: P. Bellvert; Saint Jean De Luz: J. Saint-Pie; Saint Martin Boulogne: P-A. Maignan; Saint Pierre: C. Arvin-Berod, P. Poubeau; Saint Quentin: T. Fontaine, H. Kafe, P. Rohart; Salon De Provence: B. Hugues; Saumur: B. Thomas; Selesta: S. Taieb; Sete: A. Rigaud; Soissons: A. Ittah, D. Proisy; St Aubin Les Elbeuf: P. David, C. Vincent; St Brieuc: P. Bihet; St Denis: D. Penaud; St Die: E. Marangoni; St Etienne: D. Mounier; Ste Feyre: S. Jeandeau; St Laurent Du Var: G. René Boyer; St Nazaire: X. D'arco, J. Garnier, E. Michaud, A. Berthier; Tarbes: A. Prud'homme, J. CourdeauLaborie, J-A. Silvani; Tergnier: M. Monsigny; Thionville: Y.
Bassegoda, A. Beraud, J. Duc, D. Logros, A. Plaindoux; Toul: M-A. Vincent; Toulouse: C. Aldegheri, C. Raspaud, D. Giamarchi, C. Hermant, M. Krempf, H. Perelroizen, P. Bernard; Tours: J-P. Maffre; Troyes: J-P. Hurdebourcq; Tulle: JL. Bouyer; Vandoeuvre: X. Feintrenie, B. Mouget, J-M. Polu; Vendome: S. Hourie; Verdun: J-C. Cornu; Villefranche Sur Saône: L. Falchero; Villeneuve Sur Lot: A. Razafimdramboa; Voiron: MH. Laussedat.

\section{REFERENCES}

1 Wedzicha JA, Donaldson GC. Exacerbations of chronic obstructive pulmonary disease. Respir Care 2003; 48: 1204-1213.

2 White AJ, Gompertz S, Stockley RA. Chronic obstructive pulmonary disease. 6 . The aetiology of exacerbations of chronic obstructive pulmonary disease. Thorax 2003; 58: 73-80.

3 Strassels SA, Smith DH, Sullivan SD, Mahajan PS. The costs of treating COPD in the United States. Chest 2001; 119: 344-352.

4 Seemungal TAR, Donaldson GC, Bhowmik A, Jeffries DJ, Wedzicha JA. Time course and recovery of exacerbations in patients with chronic obstructive pulmonary disease. Am J Respir Crit Care Med 2000; 161: 1608-1613.

5 Kanner RE, Anthonisen NR, Connett JE, Group TLHSR. Lower respiratory illnesses promote $\mathrm{FEV}(1)$ decline in current smokers but not ex-smokers with mild chronic obstructive pulmonary disease: results from the lung health study. Am J Respir Crit Care Med 2001; 164: 358-364.

6 Seemungal TAR, Donaldson GC, Paul EA, Bestall JC, Jeffries DJ, Wedzicha JA. Effect of exacerbation on quality of life in patients with chronic obstructive pulmonary disease. Am J Respir Crit Care Med 1998; 157: 1418-1422.

7 Tashkin DP, Cooper CB. The role of long-acting bronchodilators in the management of stable COPD. Chest 2004; 125: 249-259.

8 Casaburi R, Mahler DA, Jones PW, et al. A long-term evaluation of once-daily inhaled tiotropium in chronic obstructive pulmonary disease. Eur Respir J 2002; 19: 217-224.

9 Vincken W, van Noord JA, Greefhorst APM, et al. Improved health outcomes in patients with COPD during 1 yr's treatment with tiotropium. Eur Respir J 2002; 19: 209-216.

10 Brusasco V, Hodder R, Miravitlles M, Lee A, Towse LJ, Kesten S. Health outcomes in a 6-month placebo controlled trial of once-daily tiotropium compared with twice-daily salmeterol in patients with COPD. Thorax 2003; 58: 399-404.

11 O'Donnell DE, Flüge $\mathrm{T}$, Gerken $\mathrm{F}$, et al. Effects of tiotropium on lung hyperinflation, dyspnea and exercise tolerance in patients with COPD. Eur Respir J 2004; 23: 832-840.

12 Celli B, ZuWallack R, Wang S, Kesten S. Improvement in resting inspiratory capacity and hyperinflation with tiotropium in COPD patients with increased static lung volumes. Chest 2003; 124: 1743-1748.

13 Niewoehner DE, Rice K, Cote C, et al. Prevention of exacerbations of chronic obstructive pulmonary disease with 
tiotropium, a once-daily inhaled anticholinergic bronchodilator: a randomized trial. Ann Intern Med 2005; 143: 317-326.

14 Friedman M, Menjoge SS, Anton SF, Kesten S. Healthcare costs with tiotropium plus usual care versus usual care alone following 1 year of treatment in patients with chronic obstructive pulmonary disorder (COPD). Pharmacoeconomics 2004; 22: 741-749.

15 Oostenbrink JB, Rutten-van Molken MP. Resource use and risk factors in high-cost exacerbations of COPD. Respir Med 2004; 98: 883-891.

16 Oostenbrink JB, Rutten-van Mölken MPMH, van Noord JA, Vincken W. One-year cost-effectiveness of tiotropium versus ipratropium to treat chronic obstructive pulmonary disease. Eur Respir J 2004; 23: 241-249.

17 Quanjer PH. Standardised lung function testing of the European Community for Coal and Steel. Bull Eur Physiopathol Respir 1983; 19: 7-10.

18 Global Initiative for Chronic Obstructive Lung Disease. Global strategy for the diagnosis, management, and prevention of chronic obstructive pulmonary disease. Update 2004. www.goldcopd.com. Last updated: September 2005; last accessed: 20 August 2004.

19 Verkindre C, Bart F, Aguilaniu B, et al. The effect of tiotropium on hyperinflation and exercise capacity in COPD. Respiration 2006 (in press).

20 Roche N, Lepage T, Bourcereau J, Terrioux P. Guidelines versus clinical practice in the treatment of chronic obstructive pulmonary disease. Eur Respir J 2001; 18: 903-908.

21 Rodriguez-Roisin R. Toward a consensus definition for COPD exacerbations. Chest 2000; 117: 398-401.

22 Disse B. Antimuscarinic treatment for lung diseases from research to clinical practice. Life Sci 2001; 68: 2257-2564.

23 Anthonisen NR, Manfreda J, Warren CPW, Hershfield ES, Harding GKM, Nelson NA. Antibiotic therapy in exacerbations of chronic obstructive pulmonary disease. Ann Intern Med 1987; 106: 196-204.

24 Calverley PM, Koulouris NG. Flow limitation and dynamic hyperinflation: key concepts in modern respiratory physiology. Eur Respir J 2005; 25: 186-199. 